\title{
Types of Mycotoxins and different approaches used for their detection in foodstuffs
}

Rasha M. Elkenany, Amal Awad

Department of Bacteriology, Mycology, and Immunology, Faculty of Veterinary Medicine, Mansoura University, Mansoura 35516, Egypt

\section{ARTICLE HISTORY}

Received: 26.08 .2020

Revised: 16.03 .2021

Accepted: 20.03.2021

Address correspondence to Rasha M. Elkenany; Tel. +201021276993, E-mail: dr_rashavet22@yahoo.com
ABSTRACT

\begin{abstract}
Mycotoxins are toxic complexes generated by various genera of filamentous fungi and pose severe public health hazards due to their carcinogenic and mutagenic properties. Toxigenic fungi produce mycotoxins on various foodstuffs when favorable conditions for their production are exist. The most important mycotoxinproducing fungal genera are Aspergillus, Fusarium and Penicillium. The major mycotoxin of concern, including aflatoxins, trichothecenes, ochratoxins, patulin, fumonisins, and zearalenone, are expressively contaminate foodstuffs, with implications for human and animal health. There are various environmental factors influencing mycotoxin production involving temperature, water activity, animal type, aeration, $\mathrm{pH}$, light, and nature of substrate. The temperature and relative moistness range for ideal mycotoxin generation may shift from that steady fungal development. The high temperature and moistness stress primarily have a potential issue. A full understanding of the existence of mycotoxins in addition the implementation measures to overcome their contamination of foodstuffs is crucial. There are different important analytical techniques to precisely screen the levels of mycotoxins contamination and give a wider overview about what is the most common, pathogenic; along with further strategies to control measures. Thus, in this review sampling, sample preparation and different analytical methods for determination of mycotoxins have been discussed.

Keywords: : Mycotoxins in foodstuffs
\end{abstract}

\section{INTRODUCTION}

Mycotoxins are secondary metabolites of low molecular weight, created by number of micromycets mostly related to the genera Aspergillus, Fusarium, and Penicillium, which ubiquitously colonize foodstuffs. Mycotoxin contamination occurs either directly by consumption of the contaminated food or indirectly through animals fed on contaminated feed, particularly milk. Mycotoxins are harmful to humans and animals causing a variety of syndromes from gastroenteritis to cancer [1]. The identification and chemical characterization of several mycotoxins have been documented. Somewhat small number of mycotoxins can progress on foodstuffs for instance cereals, dried fruits, nuts and spices. Among these mycotoxins, aflatoxins, trichothecenes, ochratoxins, patulin, fumonisins, and zearalenone, significantly contaminate foodstuffs, with existent implications for human and animal health and thus are considered a public health concern [2]. Mycotoxins are recognized to be either carcinogenic (aflatoxin B1, ochratoxin and fumonisins B1); estrogenic (zearalenone), neurotoxic (fumonisins B1), nephrotoxic (ochratoxin), dermatotoxic (trichothecenes); or immunosuppressive (aflatoxin B1 and ochratoxin A) $[3,4]$. The existence of fungi does not essentially indicate the production of mycotoxins, and not all fungal development results in mycotoxin development not all fungal growth consequences in mycotoxin construction [5].

It is vital to notice that the circumstances encouraging for fungal growth and improvement in foodstuffs and stored grains are not continuously helpful for mycotoxin production. Many foodstuffs and cereals are liable to fungal contamination either in the field or throughout storage. There are many factors affecting mycotoxin production on foodstuffs and stored grains, including environmental factors (temperature, water activity, $\mathrm{pH}$, light, and nature of substrate, primarily control the mycotoxin production). Temperature and relative humidity range are the two environmental factors; vary for optimal mycotoxin production and fungal growth. Overall, mycotoxins are optimally produced at $24-28^{\circ} \mathrm{C}$. Increasing humidity and temperature in the tropical and subtropical districts than in the temperate areas increase the vulnerability of crops to mycotoxin contamination [6]. Therefore, the effectiveness of climatic variations could be an issue on mycotoxigenic fungal contamination of crops. Consequently, it is hard to designate a single set of optimum circumstances for fungal growth and mycotoxin production [7]. Additionally, poor harvesting practices, improper storage, marketing and processing could favor the fungal growth and raise the dangerous of mycotoxin production. All of these interrelating factors warranted the need for production of mycotoxin free grains and foodstuffs in the last decade. 
Accurate diagnosis by using satisfactory laboratory methods to differentiate mycotoxicosis from other infections and to identify the causal mycotoxin is very important to reduce economic losses and reducing public health hazards. Identification of mycotoxicosis is essential to distinguish affected animals and know how to deal with them. In addition, diagnosis is essential to choose and test the food consumed by affected animals and to manage such contaminated food either by thrown away or dilute with good food and to control the transportation, storage and handling of the similar type of food. As well, the diagnosis assists in dealing with the products originated from the affected animals. Mycotoxicosis diagnosis, allow treatment plans to be considered. Not only these contribute has reduced economic losses but also prohibited public health hazards. This article provides an insight on the most predominant types of mycotoxins, factors affecting their production and methods used for extraction and cleanup of mycotoxins from foodstuffs. In addition, the traditional and new analytical approaches for the determination of mycotoxins were reported.

\section{TYPES OF MYCOTOXINS}

\subsection{Aflatoxins}

Aflatoxins are one of the furthermost toxic mycotoxins and formed by Aspergillus flavus and Aspergillus parasiticus that are found in soil, decaying vegetation, hay, and grains $[8,9]$. The production of aflatoxins is connected to spore formation by various Aspergillus species [10]. As well, aflatoxigenic fungi disseminate in storage zones, processing services and in the distribution schemes for manufactured products. Other less frequently aflatoxin-producing species are Aspergillus bombycis, Aspergillus ochraceoroseus, Aspergillus nomius, and Aspergillus pseudotamari [11]. From the mycological viewpoint, excessive qualitative and quantitative variances in the toxigenic aptitudes are exhibited by diverse strains in each aflatoxigenic species [12]. There are four main types of aflatoxins: B1, B2, G1, and $G 2$ depend on their fluorescence underneath UV light and relative chromatographic mobility throughout thin-layer chromatography. Aflatoxin B1 is considered as the furthermost effective natural carcinogenic toxin [13]. During processing of contaminated food, the entrance of aflatoxins to the general food source in addition to feedstocks for raising livestock, aflatoxin has been detected somewhere in both pet and human feed. somewhere aflatoxin has been present in both pet and human feed, in addition to feedstocks for farming animals. Aflatoxin transformation products in animals could be released into eggs, milk products, and meat. All cereal crops are frequently affected by Aspergillus species producing aflatoxins [14]. Even more challenging is the fate of crops kept underneath circumstances which stimulate mold growth because the furthermost significant variables are the moisture content of the substrate and the relative humidity of the surrounds during storage [15]. Aflatoxins have been detected in the milk of animals which consumed contaminated feed, these animals metabolically biotransform aflatoxin B1 into a hydroxylated form called aflatoxin M1 [16]. Such milk is the main cause of aflatoxin outbreaks for humans [17]. Also, aflatoxin contaminated poultry diets reduced the poultry efficiency and are causing huge economic losses through poor body performance, in form of retarding bird growth, increasing feed consumption, and reducing meat production or through sequels of aflatoxin [18]. The toxicity in chickens is characterized by mortality, lethargy, anorexia, reduced growth rates, reduced efficiency of feed conversion, fatty liver, declined egg production, deprived pigmentation and raise sensitivity to other diseases [9]. High concentrations of aflatoxins could result in acute poisoning (aflatoxicosis) and so associated with high mortality in farm animals [19]. Aflatoxins have been shown to be life threatening through damage to the liver, DNA and result in animals and human liver cancer (carcinogens).

\subsection{Trichothecene}

Several fungal genera, involving Fusarium, Stachybotrys, Myrothecium, Trichothecium, Trichoderma, Cephalosporium, Cylindrocarpon, Verticimonosporium, and Phomopsis, are the trichothecene-producer $[20,21]$. Trichothecenes are categorized as macrocyclic or non-macrocyclic, dependent on the existence of a macrocyclic ester or an ester-ether bridge between C-4 and C-15 [22]. Fusarium molds are the most economically important source of the non-macrocyclic trichothecenes. The genus Fusarium comprises numerous field fungi adapt to infect plants including wheat, corn, barley, oats, and forages. Fusarium is mostly communal in temperate climates areas, where foodstuffs contamination is widespread. Trichothecenes are potent inhibitors of protein construction and have toxicity to molds, bacteria, plants, and animals [23]. Trichothecene are usually established as food and feed contaminants. The consumption of trichothecene results in hasty irritation to intestinal mucosa leading to alimentary hemorrhage, vomiting and diarrhea, while direct contact leads to dermatitis [24]. Also, chronic exposure in animals leads to suppression of the immune system.

\subsection{Ochratoxins}

Ochratoxin A is produced by numerous species of Aspergillus, involving Aspergillus alliaceus, Aspergillus auricomus, Aspergillus carbonarius, Aspergillus glaucus, Aspergillus melleus, and Aspergillus niger [25] as well as Penicillium verrucosum [26]. It is a common food-contaminants defined as a potent nephrotoxin to all animal species. contamination of food supplies with ochratoxin $A$; for examples cereals and cereal products, coffee beans, wheat, dry vine fruits, wine and grape juice, spices and other plant products, is widespread $[27,28]$. Ochratoxin A is produced throughout the storage of crops and is responsible for several toxic effects in various animal breeds. The furthermost sensitive and 
noteworthy effect is kidney impairment, but also it could negatively affect fetal expansion and the immune system. Opposing to the distinct indication of kidney toxicity and cancer commonly associated with ochratoxin A in animal species, such suggestion in humans is unclear, however its impact on kidney have been established [29]. Besides being a nephrotoxin, ochratoxin $A$ is proved to be a liver toxin, an immune suppressor, a powerful teratogen, and a carcinogen in animal species [30]. Ochratoxin had been found in blood and other animal tissues, in milk [27] and pork prepared for human ingestion [31]. Furthermore, ochratoxin is related to disease and mortalities in poultry [32].

\subsection{Patulin}

Patulin is a toxin formed by a variability of molds, particularly Aspergillus, Penicillium (P. griseofulvum; formerly Penicillium patulum and $P$. expansum) and Byssochlamys. It is frequently present in rotting apples and apple products. As well, patulin occurs in several moldy fruits, grains and other foods. Main human nutritional sources of patulin are apples and apple juice produced from contaminated fruits. Although patulin has antibacterial, antiviral, and antiprotozoal effects, it was toxic to both plants and animals [33, 34]. Thus, patulin is discontinued from its clinical uses as antibiotics and classified as mycotoxins [35]. Patulin is genotoxic and associated with the following acute symptoms in animal species; liver, spleen and kidney damage and the immune system toxicity, while in humans it is responsible for nausea, gastrointestinal disorders and vomition.

\subsection{Fumonisins}

Fumonisins are formed by several Fusarium species, especially Fusarium verticillioides, Fusarium proliferatum, and Fusarium nygamai, besides Alternaria alternata f. sp. Iycopersici [36]. Fumonisin B1 is the furthermost abundantly produced by member of the family. Fusarium verticillioides, the main species of economic importance and exist in all corn [36]. Fumonisins have showed its effects on animal species through interfering with sphingolipid metabolism [37, 38]. The most common syndromes associated with fumonisins are leukoencephalomalacia in horses (39); pulmonary edema and hydrothorax in pigs [40]; and hepatotoxicity, carcinogenicity [41] and apoptosis in the liver of rats [42]. An opportunity of esophageal cancer may occur in humans as well[43].

\subsection{Zearalenone}

Zearalenone is one of the mycotoxin formed by numerous Fusarium species, principally $F$. graminearum and further species as Fusarium crookwellense, Fusarium culmorum, and Fusarium equiseti, that are regularly contaminating cereal crops [44]. The biological effectiveness of such mycotoxins is significant, but the real toxicity is slight. Higher concentrations of zearalenone consumption (zearalenone toxicosis) increase estrogenic activity and result in disturbed conception, abortion, and other reproductive problems such as infertility, vulval edema, and feminization of males in many animal species; particularly swine, cattle and sheep $[45,46]$.

\section{FACTORS AFFECTING MYCOTOXIN PRODUCTION}

\subsection{Temperature and water activity}

The temperature and water activity are the most important parameters influencing thegrowth of fungi producing mycotoxin and mycotoxin synthesis. Furthermost fungal species make a maximum level of mycotoxins at their optimum growth temperature. Generally, mycotoxins are optimally produced at $24-28^{\circ} \mathrm{C}$, though some exceptions may be found. The lowest and optimum temperatures and water activity for growth and mycotoxin production of the foremost mycotoxinproducing fungal species are various [47, 48]. The warm conditions are favorable for aflatoxin producer so, the tropical and subtropical areas demonstrate high existence of mycotoxins [49]. The optimum temperature and water activity for aflatoxin producing were $33^{\circ} \mathrm{C}$ and 0.99 , successively [50]. Although toxin formation still obvious at $32^{\circ} \mathrm{C}$, temperatures overhead $33^{\circ} \mathrm{C}$ evidently interfere aflatoxin producing even supposed enhancement of fungal growth was occurred [51]. The toxins are not produced at low temperature $\left(8^{\circ} \mathrm{C}\right)$. A higher toxin production by Fusarium species occurs after incubation at a low temperature of $12-14^{\circ} \mathrm{C}$ [52].

Depending on the moisture necessities, mycotoxinproducing fungi have been classified into three sets: field fungi, storage fungi, and advanced decay fungi. The field fungi include species of the genera Alternaria and Fusarium. The storage fungi primarily comprise species of the genera Aspergillus and Penicillium [53]. The advanced decay fungi contain species of the genera Cladosporium, Fusarium, and Trichoderma [54]. The field fungi producing mycotoxin need a grain moisture contented of $22-25 \%$, whereas storage mycotoxin producing frequently require a grain moisture of 13$18 \%$ (equivalent to $70 \%$ to $90 \%$ relative humidity), and advanced decay fungi grow in more than $18 \%$ moisture [55]. Grains and stored crops underneath these environments could simply be affected by fungi mycotoxin-producers [56]. Consequently, the dominant mycotoxin contamination of grains and crops in tropical and subtropical areas is associated with a great health hazard.

\subsection{Atmosphere}

The adapted atmosphere with raised up carbon dioxide and diminished oxygen levels has inhibitory effect on the growth and mycotoxin producing of toxic fungal species [57].

\subsection{Nature of substrate (foodstuffs)}

There are a lot of foodstuffs, including cereal grains (wheat, rice, corn, maize, and sorghum), oilseeds (sunflower, peanut, cottonseed, and soybean), spices (black pepper, chillies, and 
ginger), tree nuts (pistachio, coconut, and walnut), which may be affected with mycotoxins, whereas peanuts and maize are the furthermost liable foodstuffs [58] due to peanuts growth in the soil, numerous fungal species affect peanut shell, testa, and seed. Also, any mechanical impairment throughout harvest, drying, and storage rises the accidental fungal infection, fungal growth and mycotoxin creation (Ref.). Milk of animal and human and milk products as cheese, and butter could be a base of mycotoxin contamination upon consumption[49].

\subsection{Animal species}

Monogastric farm animals as chickens and pigs are more vulnerable to mycotoxins, particularly aflatoxins. There are two reasons for such high susceptibility: firstly, they consumed a large part of cereals in their food. Secondly, these animals are deficient in the ruminal reservoir of a multitude of microorganisms. However, ruminants appear to be less vulnerable to mycotoxins rather than other animals because their rumenal flora have the capacity to transform some mycotoxins into less carcinogenic metabolites or biologically inactive compounds [59].

\section{5. $\mathrm{pH}$}

The synthesis of mycotoxins is observed on acidic $\mathrm{pH}$ [60]. For example, the $\mathrm{pH}$ level for Aspergillus niger growth and its mycotoxin production is from 4 to 6.5 [61].

\subsection{Light}

UV and fluorescent light have the capacity to detoxify mycotoxins or hinder the synthesis of mycotoxins to diminish their hazardous effects. For example, some mycotoxins produced by Aspergillus parasiticus, Fusarium verticillioides, Scopulariopsis fusca and Verticillium lecanii were completely eliminated when they exposed to fluorescent light, short and long UV and kept for three weeks underneath diverse relative humidity (50-80\%) at room temperature [62].

\subsection{Other factors}

More mycotoxin contamination can be detected in subtropical and tropical countries with poor infrastructures such as processing facilities, transportation, storage, and skilled human resources [63].

\section{DETECTION OF MYCOTOXINS}

\subsection{Sampling}

It is very important to obtain a representative samples for determining mycotoxins. Mycotoxins usually are not evenly distributed in stored commodities and tend to generated in isolated pockets. In addition, due to its heterogeneity there are difficulties in collecting representative samples. The inconsistency connected with mycotoxins analyses decreases by intensifying the sample size, degree crushing, subsample size, and the amount of aliquots quantified [64]. For liquid dairy products s milk, there is no doubt in the detection results. However, in solid products as cheese, it is imperative to get a homogenous sample. Therefore, the whole sample is necessity to be crushed and mixed carefully before starting analysis to have the same concentration of toxin. The European Commission (EC) has defined necessities for collecting samples and performance criteria for analytical techniques to obtain comparable data [65]. Therefore, sampling, extraction and clean up and determining methods used have to subject to a validation procedure to meets all performance criteria.

\subsection{Extraction and cleanup}

Analytical methods based on chromatography necessitate using appropriate solvents to liberate the mycotoxin from the sample matrix. Therefore, samples preparation is very important which involves two important steps of extraction and clean-up. Extraction methods are strongly affected the recovery of the specific compounds and therefore the accuracy of the results. A suitable extraction solvent should be efficient to remove mycotoxins, inexpensive, safe to the user, and reduces matrix effect. The extraction techniques should be fast and effective and of low costs. Additionally, environmental pollution due to using a chlorinated solvent should be taken in consideration. Various combinations of solvents are used for extraction. Organic solvents are frequently used in the extraction protocols such as methanol, acetone, based on the physical properties of mycotoxins on interest, matrix of samples and the subsequent type of clean-up performance [66]. While, water can be used for extraction of polar mycotoxins, as well as non-polar organic solvents used for other compounds. Sample pretreatment methods include many techniques for examples liquid-liquid extraction (LLE), supercritical fluid extraction (SFE), solid phase extraction (SPE).

\subsubsection{Liquid-liquid extraction (LLE)}

The liquid-liquid partitioning or extraction (LLE) is depended on the dissemination of analytes in two nonmiscible stages, wherever the analyte is transmitted from one stage into the other. The compound is extracted into one solvent separating from the rest of the matrix in the other. The phases are frequently an aqueous solvent (hydrophilic) and a hydrophobic organic solvent [67]. Therefore, solvents as cyclohexane and hexane are useful to eliminate non-polar contaminants, e.g. lipids and cholesterol [68]. Though, it is time consuming, and is dependent on which matrix is useful, and which complexes are been detected. Difficulties of this strategy are with probable loss of sample by adsorption onto the glassware, the elevated amounts of applied organic and previously chlorinated solvents, and formation of emulsions. New establishments in LLE comprise the usage of aqueous twophase polymeric systems, aqueous two [69].

\subsubsection{Supercritical fluid extraction (SFE) usages}


SFE practices a supercritical fluid as carbon dioxide for extraction of the essential complex from the matrix. Such technique is properly performed because of the elevated solvating power, and density of the solvating liquid, on the other hand it is not an effective technique due to the complications linked to SFE. As well as, such technique is unsuitable for repetitive analysis because of its high costs [70].

\subsubsection{Solid phase extraction (SPE)}

Solid phase extraction is dependent on the difference of chromatographic techniques using one-use cartridges full with silica gel. In solid phase extraction, the sample is overloaded in one solvent, commonly underneath reduced pressure followed by rinsing to eliminate the contaminants and then eluted in another solvent [71].The cartridges can bind of small molecules. Overall, SPE is more effective than LLE, easily to achieve, quickly and could be certainly automated. Furthermore, there is no requirement for usage of chlorinated solvents; in addition a lesser amount of organic solvent is needed and less timewasting.

\subsection{Analytical techniques}

\subsubsection{Conventional analytical techniques}

There are different common conventional chemical analytical methods applied for detection of mycotoxins from various samples which refer to chromatographic separation combined with a suitable detection system. High performance liquid chromatography (HPLC) with diverse detectors is used commonly for routine analyses and as confirmatory technique for the modern techniques [72]. Mass spectrometer is the detector of choice rather than tandem mass spectrometer [73]. Fluorometric detector for HPLC is common because of its sensitivity, low cost and simplicity, though derivatization is required for most mycotoxins. Also, other detectors for HPLC are applied, particularly Ultra Violet-spectrometric. Gas chromatography (GC) is frequently used for detection of some mycotoxins such as volatile mycotoxins, followed by electrophoretic methods, modern thin-layer chromatography and others [74].

\subsubsection{Thin layer chromatography (TLC) Method}

TLC is a prevalent technique applied for mycotoxin analysis, due to its capability to investigate great numbers of samples, low operating cost and simplicity of determination of target compounds [75]. TLC techniques practice percentage has declined to reach $7 \%$ in 2002 , but this method is still recommended for quantitative and semi-quantitative purposes [76]. Such method is applied as a qualitative process, after coupled with densitometry it becomes used more for quantitative analysis. However, TLC is essentially requires sample preparation and clean up protocol based on the physical characteristics of the matrix and the kind of the toxin. Silica gel columns used for purification of mycotoxins. Nowadays, TLC methods are still used for the recognition of aflatoxin (AF) in some plant material. Due to its low costs and less equipment required, TLC techniques are occasionally performed for the detecting mycotoxins in raw herbal drug substances. Numerous progressive techniques have been applied throughout the last years for the mycotoxin quantitative assessment in food and cereals.

\subsubsection{High Performance Liquid Chromatography (HPLC)}

It is quantitate method used as a reference technique for mycotoxins detection. It is expensive and needs qualified persons. Its separating is frequently attained on $C_{18}$ reversed phase columns with methanol/water mixtures as mobile phase [77]. Current analysis of mycotoxins deeply depends on HPLC using numerous adsorbents dependent on the physical and chemical structure of the mycotoxin. Normal and reversedphase columns are applied for separating and purifying toxins basing on their polarity. Small mini columns are performed for sample pretreatment and large scale preparative columns are applied for preparing mycotoxin standards [78].

High-performance liquid chromatography (HPLC) with a FLD detector

It is the furthermost generally used approach for Aflatoxins (AF) detection in herbal medicine mediums. $A F B_{1}$ and $\mathrm{AFG}_{1}$ fluorescence is expressively quantified by aqueous solvent mixtures in reverse-phase chromatography. Consequently, a derivatization reaction is naturally applied for identification. Over the previous years, both pre- and post-column derivatization protocols have been recommended.

Ultra-high performance liquid chromatography (UPLC) is lately carried out to detect mycotoxins in herbal medicines [79]. UPLC improve chromatographic resolution compared to traditional HPLC and UPLC, in addition, it is more sensitive and less time consuming which is more appropriate for highthroughput determination of trace complex mixtures.

\subsubsection{Rapid Screening Technologies for Mycotoxin Analysis}

Immunological techniques are rapid qualitative analyses carried out for detecting mycotoxins in herbal medicines. Immunological methods mostly used for rapid screening. These techniques characterized by simplicity of sample preparation, low costs. Conversely, it sometime gives false-positive results

\subsubsection{Enzyme-Linked Immunosorbent Assay (ELISA)}

ELISA is immune response between antigen and specific antibody in presence of catalytic enzyme [80]. ELISA is commonly used because it is rabid, simple and somewhat inexpensive technique. There are some commercial kits used in ELISA technique used for detection on common mycotoxins such as AFs, OTA, trichothecenes, FBs, and CIT [81]. Most of these kits applied for determination of mycotoxins in foodstuff. Because of the complex co-extract of herbal samples, leads to unspecific reactions of antibodies, results in mis-calculation [82]. 


\section{Conclusion}

Mycotoxins are toxic metabolic substances formed due to improper feed storage and may result in massive outbreak of diseases in humans and animals. The most important types of mycotoxins posing potential hazards comprise aflatoxins, trichothecene, ochratoxin, patulin, fumonisins, and zearalenone. Environmental factors, such as temperature, water activity, atmosphere, $\mathrm{pH}$, and light, may considerably affect fungal growth and mycotoxin formation in foodstuffs. Thoughtful the influences of these factors are useful to develop the efficient strategies for controlling mycotoxigenic fungi and mycotoxin production. In addition, the recent diagnostic methods of mycotoxigenic fungi and mycotoxins detection assist the developing of control measures to reduce mycotoxin formation. Consequently, this review helps in understanding different types of mycotoxins, factors affecting mycotoxin production, and recent methods for their diagnosis. Further research studies are necessary to give a better understanding of fungal control approaches, involving environmental and biological measures.

\section{Conflict of interest statement}

No conflict of interest.

\section{Authors'contribution}

Rasha M. Elkenany and Amal Awad shared in writing and revision the paper and took the responsibility of correspondence to the journal. All authors approved the final version of the manuscript for publication.

\section{REFERENCES}

[1]. Adams MR, Motarjemi Y. Basic food safety for health workers: World Health Organization; 1999 Contract No.: Document Number|.

[2]. Wagacha JM, Muthomi JW. Mycotoxin problem in Africa: current status, implications to food safety and health and possible management strategies. International journal of food microbiology. 2008;124:1-12. https://doi.org/10.1016/j.ijfoodmicro.2008.01.008

[3]. Jestoi M, Rokka M, Yli-Mattila T, Parikka Pi, Rizzo A, Peltonen K. Presence and concentrations of the Fusarium-related mycotoxins beauvericin, enniatins and moniliformin in Finnish grain samples. Food additives and $\begin{array}{lll}\text { contaminants. 2004; } & \end{array}$ https://doi.org/10.1080/02652030410001713906

[4]. Coronel MB, Sanchis V, Ramos AJ, Marin S. Ochratoxin A: presence in human plasma and intake estimation. Food Science and Technology International. 2010; 16:5-18. https://doi.org/10.1177/1082013209353359

[5]. Binder EM, Tan LM, Chin L, Handl J, Richard J. Worldwide occurrence of mycotoxins in commodities, feeds and feed ingredients. Animal feed science and technology. 2007;137:265-82. https://doi.org/10.1016/j.anifeedsci.2007.06.005

[6]. Thompson C, Henke SE. Effect of climate and type of storage container on aflatoxin production in corn and its associated risks to wildlife species. J Wildl Dis. 2000;36:172-9. https://doi.org/10.7589/0090-3558-36.1.172

[7]. Shapira R, Paster N. Control of mycotoxins in storage and techniques for their decontamination. Mycotoxins in food: Elsevier; 2004. p. 190-223. https://doi.org/10.1533/9781855739086.2.190

[8]. Gourama H, Bullerman LB. Aspergillus flavus and Aspergillus parasiticus: Aflatoxigenic fungi of concern in foods and feeds: A review. Journal of Food Protection. 1995;58:1395-404. https://doi.org/10.4315/0362-028X58.12.1395
[9]. Rangsaz N, Ahangaran MG. Evaluation of turmeric extract on performance indices impressed by induced aflatoxicosis in broiler chickens. Toxicology and industrial health. 2011;27:956-60. https://doi.org/10.1177/0748233711401262

[10]. Calvo AM, Wilson RA, Bok JW, Keller NP. Relationship between secondary metabolism and fungal development. Microbiology and molecular biology reviews. 2002;66:447-59. https://doi.org/10.1128/MMBR.66.3.447459.2002

[11]. Peterson SW, Ito $Y$, Horn BW, Goto T. Aspergillus bombycis, a new aflatoxigenic species and genetic variation in its sibling species, A. nomius. Mycologia. 2001;93:689-703 https://doi.org/10.1080/00275514.2001.12063200

[12]. Klich MA, Pitt J. Differentiation of Aspergillus flavus from A. parasiticus and other closely related species. Transactions of the British Mycological Society. 1988;91:99-108. https://doi.org/10.1016/S0007-1536(88)80010$\mathrm{X}$

[13]. Qi LN, Bai T, Chen ZS, Wu FX, Chen YY, De Xiang B, et al. The p53 mutation spectrum in hepatocellular carcinoma from Guangxi, China : role of chronic hepatitis B virus infection and aflatoxin B1 exposure. Liver Int. 2015;35:999-1009. https://doi.org/10.1111/liv.12460

[14]. Brown RL, Chen ZY, Cleveland TE, Russin JS. Advances in the development of host resistance in corn to aflatoxin contamination by Aspergillus flavus. Phytopathology. https://doi.org/10.1094/PHYTO.1999.89.2.113

1999;89:113-7.

[15]. Wilson DM, Payne GA. Factors affecting. The toxicology of aflatoxins: Human health, veterinary, and agricultural significance. 1994.

[16]. Van Egmond HPe. Aflatoxin M1: occurrence, toxicity, regulation. Mycotoxins in dairy products. 1989:11-55.

[17]. Gizachew D, Szonyi B, Tegegne A, Hanson J, Grace D. Aflatoxin contamination of milk and dairy feeds in the Greater Addis Ababa milk shed, Ethiopia. Food control. 2016; 59:773-9. https://doi.org/10.1016/j.foodcont.2015.06.060

[18]. Nurul Adilah Z, Mohd Redzwan S. Effect of dietary macronutrients on aflatoxicosis: a mini-review. Journal of the Science of Food and Agriculture. 2017;97:2277-81. https://doi.org/10.1002/jsfa.8234

[19]. Schmauder HP. J. E. Smith and M. O. Moss, Mycotoxins â€" Formation, Analysis and Significance. 148 S., 54 Abb., 52 Tab. Chichester-New YorkBrisbane-Toronto-Singapore 1985. John Wiley \& Sons. 14.95. ISBN: 0471906719. Journal of Basic Microbiology. 1986;26:312. https://doi.org/10.1002/jobm.3620260514

[20]. Cole RJ, Cox RH. Handbook of toxic fungal metabolites. London; New York, USA: Academic Press.; 1981.

[21]. Scott PM, Beasley VR. The natural occurrence of trichothecenes. Beasley, VR, Trichothecene mycooxicosis: Pathophysiological effects. 1989;1.

[22]. Chu FS. Mycotoxinsâ $€^{\prime \prime}$ occurrence and toxic effect. Encyclopedia of human nutrition Academic Press, New York, NY. 1998:858-69.

[23]. Council for Agricultural S. Mycotoxins: risks in plant, animal, and human systems. Council for Agricultural; 2003.

[24]. Joffe AZ. Fusarium species: their biology and toxicology. John Wiley \& Sons; 1986.

[25]. Bayman P, Baker JL, Doster MA, Michailides TJ, Mahoney NE. Ochratoxin production by the Aspergillus ochraceus group and Aspergillus alliaceus. Applied and Environmental Microbiology. 2002;68:2326-9. https://doi.org/10.1128/AEM.68.5.2326-2329.2002

[26]. Pitt JI. Penicillium viridicatum, Penicillium verrucosum, and production of ochratoxin A. Applied and Environmental Microbiology. 1987;53:266-9. https://doi.org/10.1128/AEM.53.2.266-269.1987

[27]. Marquardt RR, Frohlich AA. A review of recent advances in understanding ochratoxicosis. J Anim Sci. 1992 Dec;70(12):3968-88. https://doi.org/10.2527/1992.70123968x

[28]. Pitt Jl. Toxigenic fungi: which are important? Med Mycol. 2000;38 Suppl 1:17-22. https://doi.org/10.1080/mmy.38.1.17.22

[29]. Creppy EE. Human Ochratoxicosis. Journal of Toxicology: Toxin Reviews. 1999;18:277-93. https://doi.org/10.3109/15569549909009258

[30]. Beardall JM. Disease in humans with mycotoxins as possible causes. Mycotoxins in Grains, Compounds Other Than Aflatoxins. 1994. 
[31]. Fink-Gremmels J. Mycotoxins: their implications for human and animal health. Vet $\quad$ Q. 1999 Oct;21:115-20. https://doi.org/10.1080/01652176.1999.9695005

[32]. Burns RB, Dwivedi P. The natural occurrence of ochratoxin A and its effects in poultry. A review: Part II. Pathology and immunology. World's Poultry Science Journal. 1986;42:48-55. https://doi.org/10.1079/WPS19860005

[33]. Ciegler A, Detroy RW, Lillehoj EB. Patulin, penicillic acid, and other carcinogenic lactones. Microbial toxins. 1971;6:409-34.

[34]. Rodricks JV, Hesseltine CW, Mehlman MA. Mycotoxins in human and animal health. Park Forest South, Illinois, Pathotox Publishers, Incorporated; 1977.

[35]. Trucksess MW, Tang Y. Solid phase extraction method for patulin in apple juice and unfiltered apple juice. Mycotoxin protocols: Springer; 2001. p. 205-13. https://doi.org/10.1385/1-59259-064-0:205

[36]. Marasas WFO, Miller JD, Riley RT, Visconti A, editors. Fumonisins occurrence, toxicology, metabolism and risk assessment. Fursarium: Paul E Nelson Memorial Symposium APS Press, St Paul, Minnesota; 2001.

[37]. Marasas WFO. Fumonisins: their implications for human and animal health. Natural toxins. 1995;3:193-8. https://doi.org/10.1002/nt.2620030405

[38]. Merrill Jr AH, Sullards MC, Wang E, Voss KA, Riley RT. Sphingolipid metabolism: roles in signal transduction and disruption by fumonisins. Environmental health perspectives. 2001;109(suppl 2):283-9. https://doi.org/10.1289/ehp.01109s2283

[39]. Marasas WFO, Kellerman TS, Gelderblom WCA, Thiel PG, Van der Lugt JJ, Coetzer JAW. Leukoencephalomalacia in a horse induced by fumonisin Bâ, isolated from Fusarium moniliforme. 1988.

[40]. Harrison LR, Colvin BM, Greene JT, Newman LE, Cole Jr JR. Pulmonary edema and hydrothorax in swine produced by fumonisin B1, a toxic metabolite of Fusarium moniliforme. Journal of Veterinary Diagnostic Investigation. https://doi.org/10.1177/104063879000200312

[41]. Gelderblom WCA, Smuts CM, Abel S, Snyman SD, Cawood ME, Van der Westhuizen L, et al. Effect of fumonisin B1 on protein and lipid synthesis in primary rat hepatocytes. Food and chemical toxicology. 1996;34:361-9. https://doi.org/10.1016/0278-6915(96)00107-X

[42]. Pozzi CR, Correa B, Xavier JG, Direito GM, Orsi RB, Matarazzo SV. Effects of prolonged oral administration of fumonisin $B 1$ and aflatoxin $B 1$ in rats. Mycopathologia.

2001;151:21-7. https://doi.org/10.1023/A:1010954119980

[43]. Sydenham EW, Shephard GS, Thiel PG, Marasas WFO, Stockenstrom S. Fumonisin contamination of commercial corn-based human foodstuffs. Journal of Agricultural and Food Chemistry. 1991;39:2014-8. https://doi.org/10.1021/jf00011a028

[44]. Haggler WM, editor. JR.; Towers, NR; Mirocha, CJ; Eppley, RM; Bryden, WL Zearalenone: Mycotoxin or mycoestrogen. Fusarium: Paul E Nelson Memorial Symposium.

[45]. Kurtz HJ, Mirocha J. Zearalenone (F2) induced estrogenic syndrome in swine, in Mycotoxic fungi, mycotoxins, mycotoxicosesâ€, vol. 2, edited by Wyllie TD and Morehouse LG. Marcel Dekker, New York, NY; 1978.

[46]. El-Nezami H, Polychronaki N, Salminen S, Mykkänen H. Binding rather than metabolism may explain the interaction of two food-grade Lactobacillus strains with Zearalenone and Its Derivative á-Zearalenol. Applied and Environmental Microbiology. 2002;68:3545-9. https://doi.org/10.1128/AEM.68.7.3545-3549.2002

[47]. Cotty P, Bayman P, Egel D, Elias K, Powell K. The genus Aspergillus. Plenm Press, New York; 1994.

[48]. Brown DW, McCormick SP, Alexander NJ, Proctor RH, Desjardins AE. A genetic and biochemical approach to study trichothecene diversity in Fusarium sporotrichioides and Fusarium graminearum. Fungal Genetics and Biology. 2001;32:121-33. https://doi.org/10.1006/fgbi.2001.1256

[49]. Bhat R, Rai RV, Karim AA. Mycotoxins in food and feed: present status and future concerns. Comprehensive reviews in food science and food safety. 2010;9:57-81. https://doi.org/10.1111/j.1541-4337.2009.00094.x

[50]. Hill RA, Wilson DM, McMillian WW, Widstrom NW, Cole RJ, Sanders TH, et al. Ecology of the Aspergillus flavus group and aflatoxin formation in maize and groundnut. Trichothecenes and other Mycotoxins. 1985;8:7995.

[51]. Mousa W, Ghazali FM, Jinap S, Ghazali HM, Radu S. Modeling growth rate and assessing aflatoxins production by Aspergillus flavus as a function of water activity and temperature on polished and brown rice. Journal of food science. 2013;78:M56-M63. https://doi.org/10.1111/j.17503841.2012.02986.x

[52]. Eugenio $C P$, Christensen $C M$, Mirocha $C$. Factors affecting production of the mycotoxin F-2 by Fusarium roseum. Phytopathology. 1970;60:1055-7. https://doi.org/10.1094/Phyto-60-1055

[53]. Miller JD. Fungi and mycotoxins in grain: implications for stored product research. Journal of Stored Products Research. 1995;31:1-16. https://doi.org/10.1016/0022-474X(94)00039-V

[54]. Fleurat-Lessard F. Integrated management of the risks of stored grain spoilage by seedborne fungi and contamination by storage mould mycotoxinsâ $\epsilon^{\prime A}$ n update. Journal of Stored Products Research. 2017;71:22-40. https://doi.org/10.1016/j.jspr.2016.10.002

[55]. Bankole SA, Adebanjo A. Mycotoxins in food in West Africa: current situation and possibilities of controlling it. African journal of Biotechnology. 2003;2:254-63. https://doi.org/10.5897/AJB2003.0001053

[56]. Osman MA, Salama A, Naguib KHM, Sherif SR. Fungi and mycotoxins associated with Egyptian sorghum grains. Moj Toxicol. 2017;3:00052. https://doi.org/10.15406/mojt.2017.03.00052

[57]. Shih CN, Marth EH. Aflatoxin produced by Aspergillus parasiticus when incubated in the presence of different gases. Journal of Milk and Food Technology. 1973;36:421-5. https://doi.org/10.4315/0022-274736.8.421

[58]. Fardiaz S, editor. Mycotoxin contamination of grains-A review of research in Indonesia. Mycotoxin contamination in grains The 17th ASEAN Technical Seminar on Grain Postharvest Technology; 1995.

[59]. Fink-Gremmels J. Mycotoxins in cattle feeds and carry-over to dairy milk: A review. Food Additives and Contaminants. 2008;25:172-80. https://doi.org/10.1080/02652030701823142

[60]. Sandoval-Contreras T, Villarruel-López A, Sierra-Beltrán AP, Torres-Vitela $\mathrm{R}$, Ascencio $\mathrm{F}$. Effect of $\mathrm{pH}$ and temperature in production of mycotoxins and antibiotics by phytopathogenic moulds for Persian lime (Citrus latifolia T.) in a complex lime pericarp-base medium. Emirates Journal of Food and Agriculture. 2017:751-9. https://doi.org/10.9755/ejfa.2017.v29.i10.1293

[61]. Passamani FRF, Hernandes T, Lopes NA, Bastos SC, Santiago WD, CARDOSO MdG, et al. Effect of temperature, water activity, and $\mathrm{pH}$ on growth and production of ochratoxin $\mathrm{A}$ by Aspergillus niger and Aspergillus carbonarius from Brazilian grapes. Journal of food protection. 2014;77:1947-52. https://doi.org/10.4315/0362-028X.JFP-13-495

[62]. ATAiLA M, Hassanein N, El-Beih A, Youssef Y. Effect of fluorescent and UV light on mycotoxin production under different relative humidities in wheat grains. ACTA Pharmaceutica Sciencia. 2004;46.

[63]. Miller JD, Savard ME, Sibilia A, Rapior S, Hocking AD, Pitt JI. Production of fumonisins and fusarins by Fusarium moniliforme from Southeast Asia. Mycologia. https://doi.org/10.1080/00275514.1993.12026290

[64]. Whitaker TB. Sampling for mycotoxins. Mycotoxins in food: detection and control. 2004:69-81. https://doi.org/10.1533/9781855739086.1.69

[65]. Koesukwiwat U, Sanguankaew K, Leepipatpiboon N. Evaluation of a modified QuEChERS method for analysis of mycotoxins in rice. Food chemistry. https://doi.org/10.1016/j.foodchem.2013.12.029

2014;153:44-51

66]. Zollner P, Mayer-Helm B. Trace mycotoxin analysis in complex biological and food matrices by liquid chromatography-atmospheric pressure ionisation mass spectrometry. J Chromatogr A. 2006 Dec 15;1136:123-69. https://doi.org/10.1016/j.chroma.2006.09.055

[67]. Cantwell FF, Losier M. Liquidâ "liquid extraction. Sampling and sample preparation for field and laboratory Comprehensive analytical chemistry Elsevier. 2002;37:297-340. https://doi.org/10.1016/S0166$526 \times(02) 80048-4$ 
[68]. Stoev S. Long term preliminary studies on toxic and carcinogenic effect of individual or simultaneous exposure to ochratoxin $A$ and penicillic acid in mice. Toxicon. 2020. https://doi.org/10.1016/j.toxicon.2020.06.013

[69]. Mazzola PG, Lopes AM, Hasmann FA, Jozala AF, Penna TCV, Magalhaes PO, et al. Liquidâ $€$ "liquid extraction of biomolecules: an overview and update of the main techniques. Journal of Chemical Technology \& Biotechnology: International Research in Process, Environmental \& Clean Technology. 2008;83:143-57. https://doi.org/10.1002/jctb.1794

[70]. Nawaz MAH, Rauf S, Hayat A, Catanante G, Raza R, Marty J-L. Determination of Mycotoxins in Food. Analysis of Food Toxins and $\begin{array}{llll}\text { Toxicants, } & 2 & \text { Volume } & \text { Set. }\end{array}$ https://doi.org/10.1002/9781118992685.ch5

[71]. Turner NW, Subrahmanyam S, Piletsky SA. Analytical methods for determination of mycotoxins: a review. Analytica chimica acta. 2009;632:168-80. https://doi.org/10.1016/j.aca.2008.11.010

[72]. Hernndez-Hierro JM, Garc-a-Villanova RJ, Gonzlez-Mart-n I. Potential of near infrared spectroscopy for the analysis of mycotoxins applied to naturally contaminated red paprika found in the Spanish market. Analytica chimica acta. 2008;622:189-94. https://doi.org/10.1016/j.aca.2008.05.049

[73]. Berthiller F, Sulyok M, Krska R, Schuhmacher R. Chromatographic methods for the simultaneous determination of mycotoxins and their conjugates in cereals. International journal of food microbiology. 2007;119:33-7. https://doi.org/10.1016/j.ijfoodmicro.2007.07.022

[74]. Xu B-j, Jia X-q, Gu L-j, Sung C-k. Review on the qualitative and quantitative analysis of the mycotoxin citrinin. Food control. 2006;17:271-85. https://doi.org/10.1016/j.foodcont.2004.10.012

[75]. Sargeant K, O'Kelly J, Carnaghan RBA, Allcroft R. The assay of a toxic principle in certain groundnut meals. Veterinary Record. 1961;73:121923.

[76]. Castro Ld, Vargas EA. Determining aflatoxins B1, B2, G1 and G2 in maize using florisil clean up with thin layer chromatography and visual and densitometric quantification. Food Science and Technology. 2001;21:11522. https://doi.org/10.1590/S0101-20612001000100024

[77]. Krska R, Welzig E, Berthiller F, Molinelli A, Mizaikoff B. Advances in the analysis of mycotoxins and its quality assurance. Food Additives and Contaminants. 2005;22:345-53. https://doi.org/10.1080/02652030500070192

[78]. Giacomelli L, Boggetti Hc, Agnelli Hc, Anunziata J, Silber JJ, Cattana R. Relevant physicochemical factors in chromatographic separation of Alternaria alternata mycotoxins. Analytica chimica acta. 1998;370:79-89. https://doi.org/10.1016/S0003-2670(98)00247-5

[79]. Wen J, Kong W, Hu Y, Wang J, Yang M. Multi-mycotoxins analysis in ginger and related products by UHPLC-FLR detection and LC-MS/MS confirmation. Food Control. 2014;43:82-7. https://doi.org/10.1016/j.foodcont.2014.02.038

[80]. Lequin RM. Enzyme immunoassay (EIA)/enzyme-linked immunosorbent assay (ELISA). Clinical chemistry. 2005;51:2415-8. https://doi.org/10.1373/clinchem.2005.051532

[81]. Rahmani A, Jinap S, Soleimany F. Qualitative and quantitative analysis of mycotoxins. Comprehensive Reviews in Food Science and Food Safety. 2009;8:202-51. https://doi.org/10.1111/j.1541-4337.2009.00079.x

[82]. Ok HE, Kim HJ, Shim WB, Lee H, Bae D-H, Chung D-H, et al. Natural occurrence of aflatoxin $\mathrm{B} 1$ in marketed foods and risk estimates of dietary exposure in Koreans. Journal of food protection. 2007;70:2824-8. https://doi.org/10.4315/0362-028X-70.12.2824 